\title{
Early development and allometric growth patterns in burbot Lota lota $\mathrm{L}$.
}

\author{
Krzysztof Kupren • Izabela Trąbska • Daniel Żarski • Sławomir Krejszeff • \\ Katarzyna Palińska-Żarska • Dariusz Kucharczyk
}

Received: 5 February 2013/Accepted: 13 July 2013/Published online: 24 July 2013

(C) The Author(s) 2013. This article is published with open access at Springerlink.com

\begin{abstract}
This study analyzed the morphological development and allometric growth patterns of Lota lota L. (burbot) larvae reared under controlled laboratory conditions. From hatching to day 50, twenty larvae were sampled each [between 1 and 14 days post-hatch (DPH)] or every second day (between 14 and $50 \mathrm{DPH}$ ) and measured under a stereoscopic microscope using analytic software. Based on the external morphology, the different stages during early development of burbot were identified: yolk sac larva 0-8 DPH [3.92-4.37 mm total length (TL)]; preflexion larva 9-26 DPH (4.57-12.06 mm TL); flexion larva (between notochord degradation and its replacement with rays) 28-34 DPH (14.00-16.34 mm TL) and postflexion larva/juvenile 36-50 DPH (18.20-29.27 mm TL). Allometric growth patterns of some parameters (e.g., total length, head length, body length, tail length, head depth, body depth, eye diameter) were modeled by a power function and described by the growth coefficient. Organogenesis and changes of body proportions in burbot larvae were more rapid and complex during the yolk sac and preflexion phase of development as larvae developed most of their sensorial, feeding, respiratory and swimming systems and after notochord flexion, when most morphological changes were related to the progressive transformation from pelagic larva to demersal larva/juvenile.
\end{abstract}

Keywords Allometric growth · Larval development · Morphological characteristics · Burbot Lota lota

\section{Introduction}

Burbot Lota lota L. is the only freshwater representative of the cod family (Gadidae). This species is widely distributed throughout the Holarctic zone and typically inhabits cold

K. Kupren $(\bowtie) \cdot$ I. Trąbska · D. Żarski · S. Krejszeff · K. Palińska-Żarska · D. Kucharczyk Department of Lake and River Fisheries, University of Warmia and Mazury in Olsztyn, Oczapowskiego 5, 10-095 Olsztyn, Poland

e-mail: krzysztof.kupren@uwm.edu.pl 
rivers and lakes (McPhail and Paragamian 2000). Burbot is presently considered to be one of the most endangered freshwater fish species in many parts of Europe (van Houdt et al. 2003, 2005; Paragamian et al. 2008; Hardy et al. 2008). The principle causes of this include the following: disturbances in habitat, inhibition of spawning migrations, overfishing, pollution and climate warming. Burbot is a highly valued fish species and also is a promising candidate for intensive aquaculture (Wocher et al. 2013).

Information on larval development of fish species is essential for a better understanding of their early life stages, priorities during early growth and size-related adaptations, and it also offers insights into fish biology and taxonomy (Gisbert 1999). There is much published data concerning various aspects of early life stages of burbot based on both field and laboratory studies. The published papers investigated the behavior and ecology of larval and juvenile burbot (Ryder and Pesendorfer 1992; Wang and Appenzeller 1998; Fischer 1999; McPhail and Paragamian 2000; Hofmann and Fischer 2001; Donner and Eckmann 2011) and also concerned identification of the basic rearing conditions, such as optimum temperature and photoperiod (Wolnicki et al. 2002; Harzevili et al. 2004, Lahnsteiner et al. 2012) and the type of food supplied (Harzevili et al. 2003; Żarski et al. 2009; Wocher et al. 2013). However, a detailed course of morphological changes during larval stages, in combination with an analysis of inflexion points in growth curves, has not been previously reported. The determination of morphological features and relative growth patterns during early development are also very important: They can contribute to fisheries management and aquaculture by characterizing normal growth patterns under specific conditions and help to optimize rearing protocols (Peña and Dumas 2009).

The aim of the present study was to describe the morphological development and allometric growth patterns for burbot larvae reared under controlled conditions.

\section{Materials and methods}

Larvae were obtained by artificial spawning of fish originating from the Odra River (northeastern Poland). Spawning was stimulated only through manipulation of thermal conditions, according to the methodology described by Żarski et al. (2009). Eggs were obtained from three females of an average weight of $720 \pm 108 \mathrm{~g}$ (mean $\pm \mathrm{SD}$ ) and were fertilized with semen from three males with an average weight of $332 \pm 79 \mathrm{~g}$. For the first month, the eggs were incubated in Weiss jars, at 3-4 ${ }^{\circ} \mathrm{C}$. After that period, until the moment of hatching, the water temperature was kept as $6{ }^{\circ} \mathrm{C}$. At the moment when the first hatched larvae were observed, eggs were transferred to water at $10{ }^{\circ} \mathrm{C}$ in order to synchronize hatching (Żarski et al. 2009). Newly hatched larvae were placed in a semi-closed laboratory recirculating system where they were stocked in two 40-L aquariums. The initial stocking density of larvae was 60 ind. $\mathrm{L}^{-1}$. Mortality was recorded daily. Survival was $29.79 \pm 1.45 \%$ (mean $\pm \mathrm{SD}$ ) to 50 days after hatching. The system was equipped with biological filtration, aeration and automatic temperature regulation $\left( \pm 0.1{ }^{\circ} \mathrm{C}\right)$. For the first week of the study, the water temperature in the tanks was $10{ }^{\circ} \mathrm{C}$. Following swim bladder inflation, the water temperature was then gradually increased from 10 to $16{ }^{\circ} \mathrm{C}$ over 3 days, and these conditions were constant until the end of the experiment. Such a thermal regime has been recommended as optimal for burbot larvae (Wolnicki et al. 2002; Harzevili et al. 2004). Specimens were exposed to a $12 \mathrm{~L}: 12 \mathrm{D}$ photoperiod. The dissolved oxygen and ammonia contents were $>80 \%$ saturation and $<0.01 \mathrm{mg} \mathrm{L}^{-1}$, respectively. Larvae were fed three times a day ad libitum with freshly hatched Artemia sp. nauplii (San 
Francisco origin). They were randomly sampled (total $n=20$ ) daily from hatch to $14 \mathrm{DPH}$ (days post-hatch) and every second day from 14 to 50 DPH. Sampled larvae were subjected to overexposure in an anesthetic solution (MS-222 at a dose of $150 \mathrm{mg} \mathrm{L}^{-1}$ ) and digital photographs of each specimen were taken using digital image analysis software ProgRes ${ }^{\circledR}$ CapturePro 2.5 (Jenoptic, Germany). After this, larvae were fixed in a $4 \%$ phosphate-buffered formaldehyde solution for further detailed examinations. Developmental stages were identified according to Kendall et al. (1984) and Dunn and Matarese (1984) and divided into four periods: yolk sac larva, preflexion larva, flexion larva and postflexion larva. The term flexion larva concerned a period of development between notochord degradation and its replacement with rays. Thresholds during early development, such as filling of the swim bladder and exogenous feeding, were considered to be achieved when at least $50 \%$ of the specimens represented this particular stage. On each digital photograph, several body proportions associated with feeding and locomotion were measured to the nearest $0.01 \mathrm{~mm}$. These measurements were snout length (SNL); head length (HL), trunk length (TRL); tail (post-anal) length (TAL); eye diameter (ED); head depth (HD); body depth (BD); tail depth at anus level (TAD); mouth (maxilla) length (ML) and total length (TL) (Fig. 1). All measurements were taken along lines parallel or perpendicular to the horizontal axis of the body (Gisbert 1999). Dead and abnormal specimens (presence of malformations) were excluded from the analysis. In yolk sac larvae, the diameter (maximum and minimum) of the ellipsoidal yolk sac was also measured and the volume $\left(\mathrm{mm}^{3}\right)$ calculated using the following formula: $V=0.1667 \times L H^{2}$; where $H$ is the minimum diameter and $L$ is the maximum diameter of the yolk sphere (Heming and Buddington 1988).

Data analysis

Growth patterns during the developmental stages were modeled by a power function of TL, and the allometric patterns were described by the growth coefficient (i.e., power function exponent) in the equation $Y=a X^{b}$, where $Y$ is the dependent variable (measured character) and $X$ is the independent variable (TL), $a$ is the intercept and $b$ is the growth coefficient. Isometric growth occurred at $b=1$ and allometric growth was positive when $b>1$ and negative when $b<1$. In addition, linear regressions were performed on log-transformed data (TL as independent variable) and the inflection points were calculated. Inflection points are the $X$ values where the slope of growth changes. The inflection points were

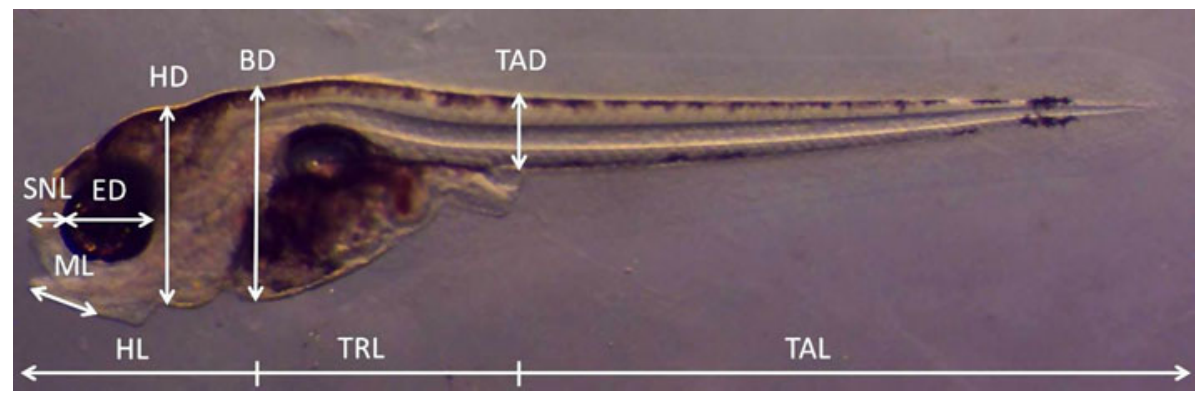

Fig. 1 Morphometric characters measured in the burbot larvae. $B D$ body depth, $E D$ eye diameter, $H D$ head depth, $M L$ mouth length, $S N L$ snout length, $T A D$ tail depth at anus level, $T A L$ tail length, $T L$ total length, $T R L$ trunk length 
calculated according to van Snik et al. (1997). The $x-y$ data set was sorted according to increasing $x$, being TL. Regression lines were calculated for $x_{\min }$ until $x_{\text {intermediate }}$, and for

$x_{\text {intermediate }}$ until $x_{\max }, x_{\text {intermediate }}$ varied iteratively from $x_{\min }+2$ to $x_{\max }-2$. Also, $t$ tests were performed to check whether the growth coefficients $\left(x_{\min } x_{\text {intermediate }}\right)$ and $\left(x_{\text {intermediate }}\right.$ $\left.x_{\max }\right)$ differed significantly. The $x_{\text {intermediate }}$ value that iteratively showed the largest $t$ was defined as the inflexion point.

No specific experiments were done to the test behavior and swimming ability of larvae. Only general observations were made in the rearing tanks during daylight and night-dark conditions and the distribution of larvae in the water column was noted.

\section{Results}

\section{Development}

Between the day of hatching and $50 \mathrm{DPH}$, the TL of the burbot larvae body (TL) grew continuously and increased by $25.35 \mathrm{~mm}$ (mean length was 3.92 and $29.27 \mathrm{~mm}$ in $0 \mathrm{DPH}$ and $50 \mathrm{DPH}$, respectively) (Fig. 2). Four larval development stages were observed after hatching: yolk sac larvae, preflexion larvae, flexion larvae and postflexion larvae. At hatching $(0 \mathrm{DPH})$, larvae measured $3.92 \pm 0.09 \mathrm{~mm}$ TL (mean $\pm \mathrm{SD}$ ) and had the head bent downwards without hatching glands (Fig. 3a). Larvae had a large yolk sac (volume $0.20 \pm 0.08 \mathrm{~mm}^{3}$, mean $\pm \mathrm{SD}$ ) containing one oil droplet in the anterior lower part of the yolk sac. A finfold covered the body from the dorsal area of the trunk to the ventral area of the yolk sac and was higher in the dorsal part of the trunk and narrowed in the caudal region. Auditory capsules and otoliths were visible in the posterior head region. The gut was an undifferentiated tube in the dorsal posterior region of the yolk sac. Melanophores were observed along the dorsal part of the body and in the posterior part of the yolk sac. The eyes were darkly pigmented. Larvae lay on the bottom and occasionally made rapid movements with the entire body and swam up from the bottom. At $3 \mathrm{DPH}$, the head was almost straight, the mouth was in more anterior position and open. On day 4 $(4.27 \pm 0.15 \mathrm{~mm}$ TL), the first larvae initiated gas bladder inflation which lasted for the next 3 days $(4.34 \pm 0.11 \mathrm{~mm}$ TL). By $8 \mathrm{DPH}, 4.38 \pm 0.14 \mathrm{~mm}$ (TL), the larvae had almost completely resorbed the yolk sac $\left(0.01 \pm 0.04 \mathrm{~mm}^{3}\right)$. The pectoral fins were well developed, and the larvae swam very well in the water column (Fig. 3b).

The preflexion stage began at the first feeding on day $9(4.57 \pm 0.13 \mathrm{~mm}$ TL) and ended around day $26(12.6 \pm 1.26 \mathrm{~mm}$ TL). At the onset of this stage, the yolk sac was resorbed but a small oil globule was still present in the anterior part of the trunk. A coiled digestive tract was evident and the anus was opened. The number of melanophores increased on the dorsal and lateral parts of the body. On day $13(5.12 \pm 0.36 \mathrm{~mm} \mathrm{TL})$, the oil globule was depleted (Fig. 3c). At $18 \mathrm{DPH}(7.58 \pm 0.70 \mathrm{~mm}$ TL), the dorsal and caudal finfold began to differentiate, starting with an indentation behind the future first dorsal fin and a slight narrowing of the finfold near the caudal peduncle. At $20 \mathrm{DPH}$ $(8.82 \pm 0.92 \mathrm{~mm} \mathrm{TL})$, the first rays appeared in the ventralmost part of the caudal fin. Two days later (22 DPH, $10.22 \pm 0.80 \mathrm{~mm}$ TL), rays also appeared on the dorsal side of the notochord tip and also in the dorsal and anal fins. At the same time, a single barbel bud located on ventral side of the lower jaw appeared (Fig. 3d). On the last day of this phase (26 DPH, $12.60 \pm 1.26 \mathrm{~mm} \mathrm{TL}$ ), a few small teeth were visible for the first time in the mouth. Most of the larvae were still homogeneously distributed in a water column, but the largest individuals began to spend more and more time near the bottom of the tanks. 


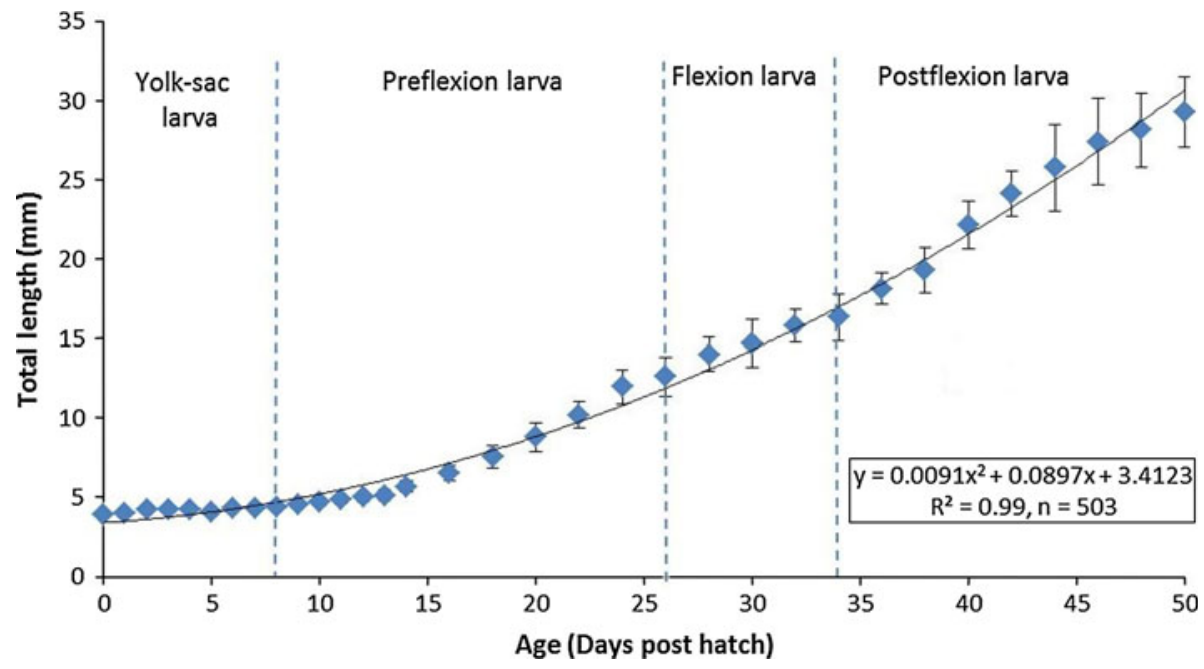

Fig. 2 Changes in total length (TL) from hatching to $50 \mathrm{DPH}$. SD (standard deviation) is represented by whiskers
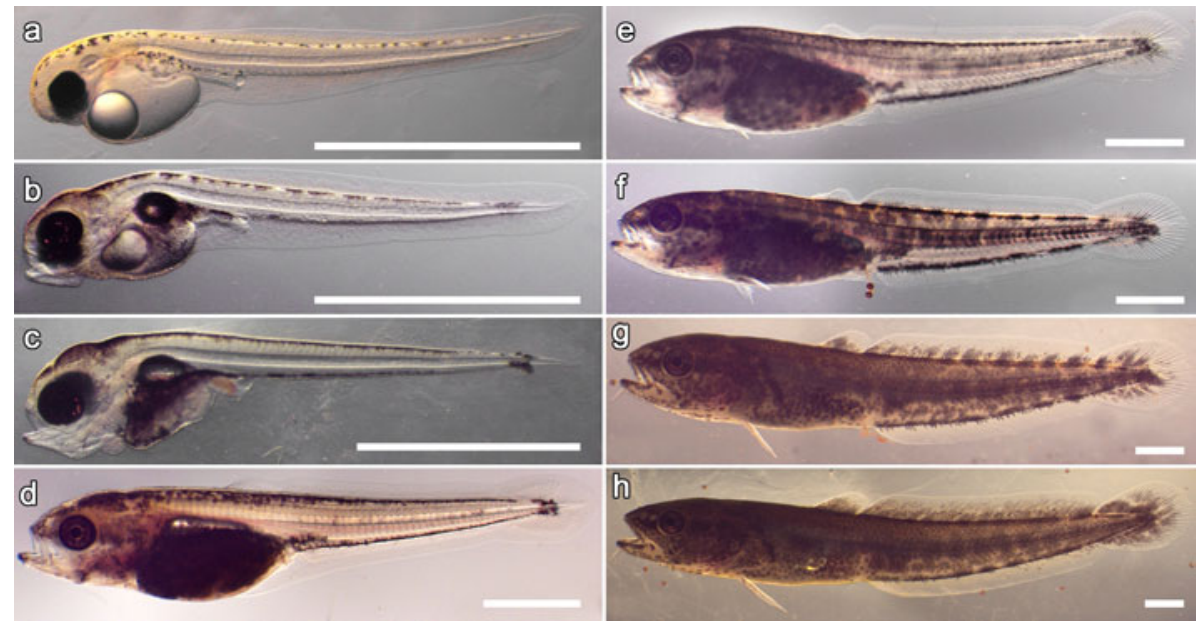

Fig. 3 Larval development of Lota lota. a Yolk sac stage ( $3 \mathrm{~h}$ ); b yolk sac stage (the gas bladder filled) (8 $\mathrm{DPH})$; c preflexion (exogenous feeding) larvae (13 DPH); d preflexion larva, (22 DPH); e flexion larva (26 $\mathrm{DPH})$; f flexion larva (34 DPH); g postflexion larva (42 DPH); h postflexion larva/juvenile (48 DPH). Scale bars $2 \mathrm{~mm}$

The flexion stage started from day $28(14.00 \pm 1.07 \mathrm{TL})$ and continued until day 34 $(16.34 \pm 1.45 \mathrm{~mm}$ TL). On day 28 , most of the larvae showed a slight upward turn of the notochord tip (Fig. 3e). During the next few days, a shortening of the notochord was observed. On day 34, the notochord was shortened and the empty place was filled by caudal rays. Pigmentation on fins was restricted to the bases (Fig. 3f). Most of the time, the larvae stayed near the bottom of the tanks.

The postflexion stage was observed from day 36 (18.12 $\pm 0.99 \mathrm{~mm}$ TL). The finfold was completely absorbed at $42 \mathrm{DPH}(24.10 \pm 1.43 \mathrm{~mm}$ TL) (Fig. 3g). Elongated pelvic, 


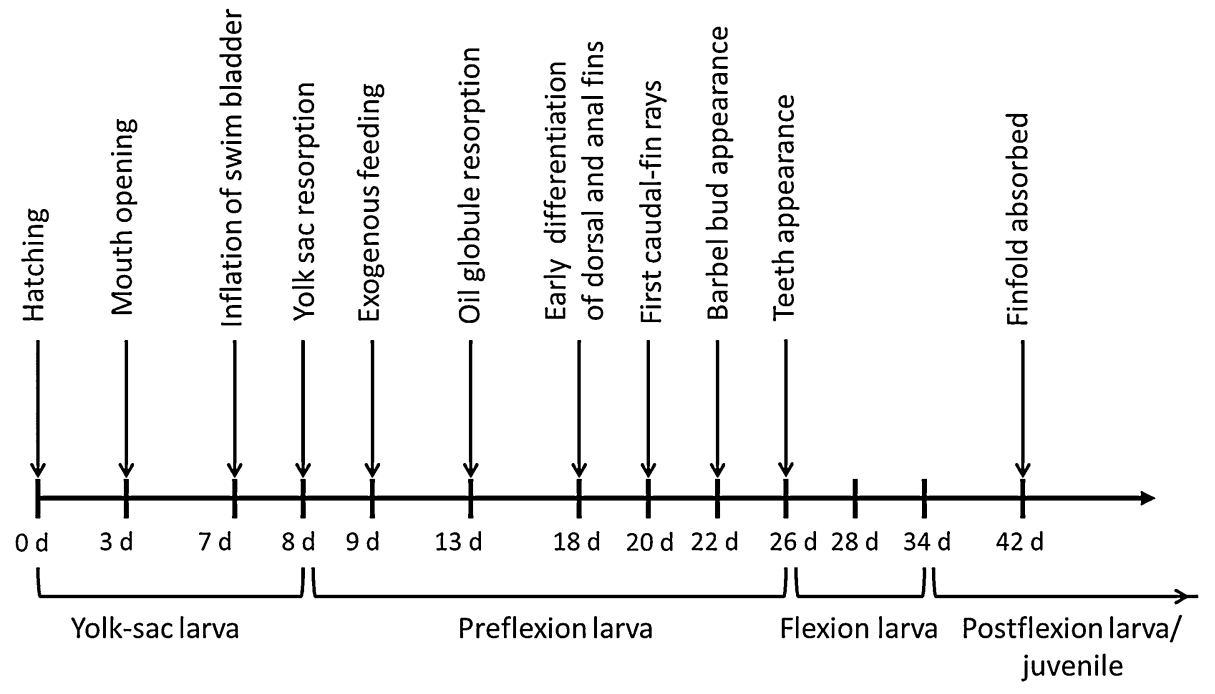

Fig. 4 The main events of larval development in burbot

anal and two dorsal fins with pigmented rays were observed. On 46 DPH $(27.39 \pm 2.18 \mathrm{~mm} \mathrm{TL})$, the second rays of the pelvic fins were visibly elongated and melanophores covered most of the fins (Fig. 3h). The body shape of larvae and the pigmentation pattern on the lateral side of the body were similar to those of the adult. Young burbots showed a completely demersal behavior.

The main events during larval development of the burbot are summarized in Fig. 4.

Allometric growth

Allometric growth equations between nine measured body segments and TL during the larval development stage (0-50 DPH) are presented in Figs. 5 and 6.

Growth of the TRL and TAL was near-isometric and monophasic ( $b=0.94, R^{2}=0.99$ and $b=0.96, R^{2}=0.99$, respectively) from hatching to 50 DPH (Fig. 5a, b). Growth of BD was monophasic and negatively allometric throughout the study ( $b=0.90, R^{2}=0.98$ ) (Fig. 5c), while the growth coefficient of TAD was positively allometric $(b=1.41$, $R^{2}=0.99$ ) (Fig. 5d). Growth of HL was positively allometric from hatching to $20 \mathrm{DPH}$ ( $\left.b=1.65, R^{2}=0.92\right)$ and isometric from 22 to $50 \mathrm{DPH}\left(b=1.00, R^{2}=0.98\right)$ with an inflexion point situated at a TL of $8.64 \mathrm{~mm}(P<0.001)$ (Fig. 6a). Growth of mouth length (ML) (measured from the time of mouth opening at $3 \mathrm{DPH})$ was positively allometric and biphasic, with faster growth during 4-24 DPH $\left(b=1.39, R^{2}=0.84\right)$ and slower growth during 26-50 DPH $\left(b=1.12, R^{2}=0.89\right)$ with an inflexion point situated at a TL of $11.76 \mathrm{~mm}(P<0.001)$ (Fig. 6b). Further, a single inflexion point was also found in the growth curve of the eye. This inflexion was situated at a TL of $8.87 \mathrm{~mm}$ from where the rate drastically decreased (20 DPH, slope $=1.02, R^{2}=0.81-0.73, R^{2}=0.94, P<0.001$ ) (Fig. 6c). A similar growth model was characteristic for HD and SNL (slope $=0.98-0.67$ and 1.44-0.63, respectively) with inflexion point at a TL of $25.10 \mathrm{~mm}$ (44 DPH, $P<0.001)$ and $27.85 \mathrm{~mm}$ (46 DPH, $P<0.001$ ), respectively (Fig. 6d, e) 

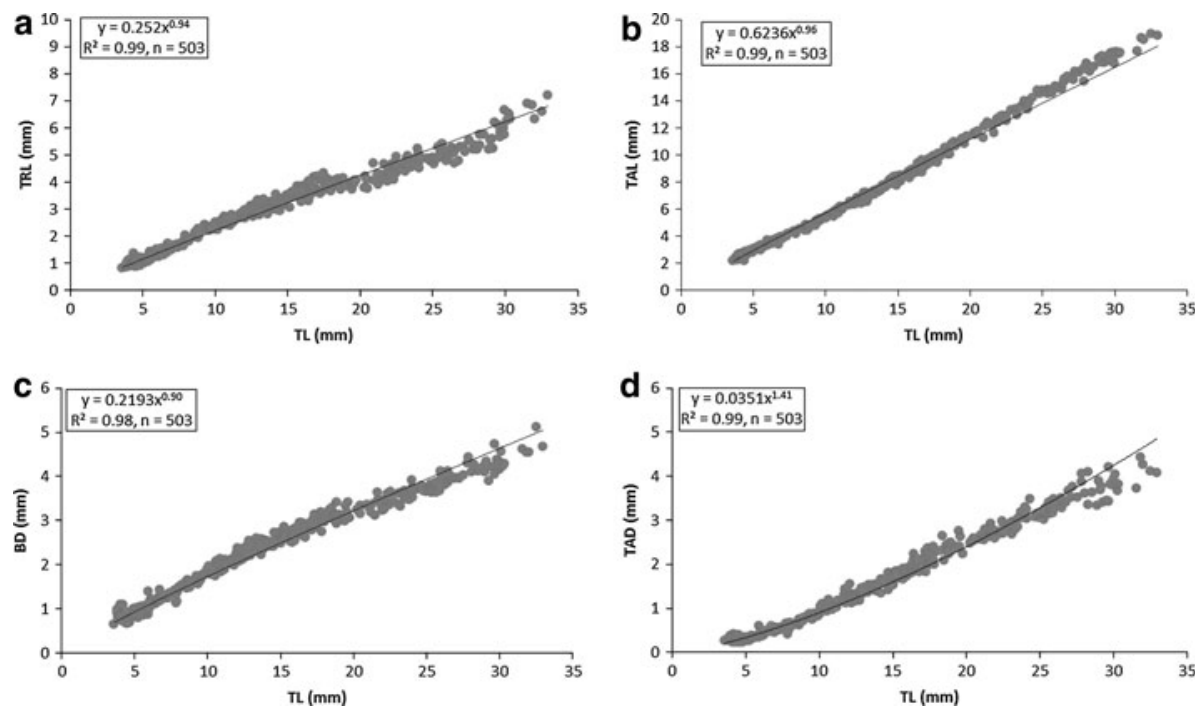

Fig. 5 Allometric growth equations between measured body proportions and total length during burbot development. The dashed line represents the inflection point of growth. TRL trunk length, TAL tail (postanal) length, $B D$ body depth, $T A D$ tail depth at anus level, $T L$ total length

\section{Discussion}

Observations on the early development of other cods (Fahay and Markle 1984; Dunn and Matarese 1984; Auditore et al. 1994) agree with the pattern described in the present study, thus confirming the basic uniformity of development in this group of fishes (Dunn and Matarese 1984). However, variations exist among species as to the relative timing of ontogenetic events and structure formation in response to different environmental conditions, e.g., temperature and food availability. Burbot follows a typical course of Gadidae ontogeny through a series of larval and juvenile stages: yolk sac larva, preflexion larva, flexion larva, postflexion larva, pelagic juvenile and demersal juvenile (Dunn and Matarese 1984; Auditore et al. 1994). Instead of true notochord flexion, which is characteristic for different teleost groups (van Snik et al. 1997; Osse and van den Boogaart 2004), there is a shortening of the notochord in burbot and other gadoid larvae (Auditore et al. 1994).

The sequence of important life events described in the present study is similar to the descriptions of this species from field-collected material (Ryder and Pesendorfer 1992; Ghan and Sprules 1993; Fischer 1999; Donner and Eckmann 2011). In lakes, the newly hatched burbot migrate upward from the deep spawning areas to the water surface to fill their swim bladders to gain buoyancy and start exogenous feeding. Next, the burbot larvae go through the pelagic phase, swim in small schools high in the water column, take vertical migrations and feed on copepods and cladocerans during the daytime (Ryder and Pesendorfer 1992; Ghan and Sprules 1993; Donner and Eckmann 2011). Upon reaching about $15 \mathrm{~mm}$, the burbot gradually undergo a habitat shift. Most of the time, they stay in the lower part of the water column near the bottom (pelagic juvenile) and when they reach about $30 \mathrm{~mm}$ in TL, they become solitary and benthic (demersal juvenile) and feed primarily at night, almost exclusively on amphipods (Ryder and Pesendorfer 1992; Wang and Appenzeller 1998; Fischer 1999). In our experiment, fish which were initially 

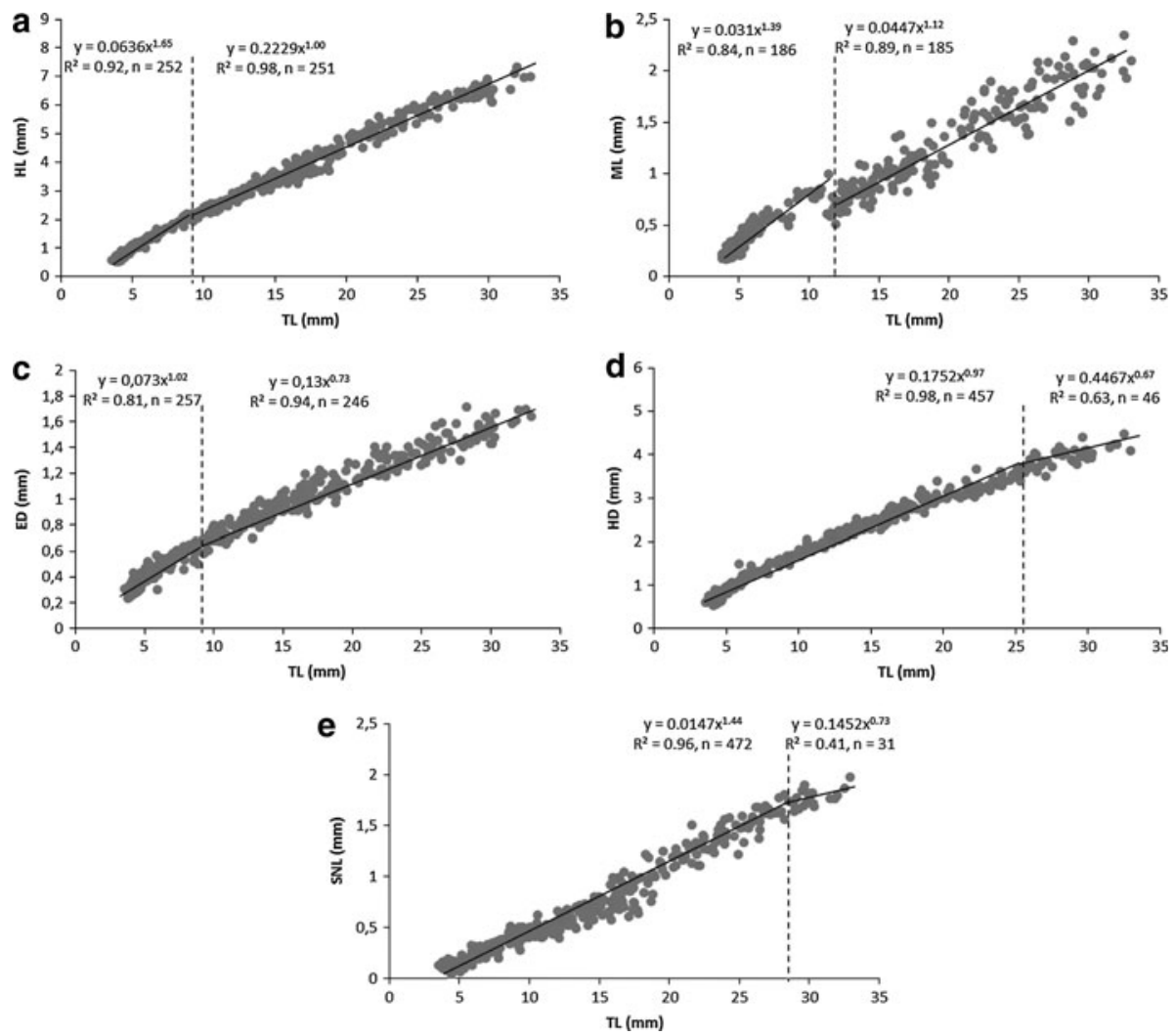

Fig. 6 Allometric growth equations between measured body proportions and total length during burbot development. The dashed line represents the inflection point of growth. $H L$ head length, $M L$ mouth (maxilla) length, $E D$ eye diameter, $H D$ head depth, $S N L$ snout length, $T L$ total length

homogeneously distributed in a water column with a good swimming ability from about 26 DPH (12.6 mm TL, end of preflexion period) gradually started to spend more time near the bottom of tanks. Such behavior was concomitant with the development of specific body structures such as teeth and barbel. This course of larval development has also been partially confirmed in several rearing experiments under laboratory conditions. Wolnicki et al. (2002), Harzevili et al. (2004), Lahnsteiner et al. (2012) and Wocher et al. (2013) found a similar TL at chosen larval stages to be important from a practical (in hatchery) point of view (e.g., yolk sac absorption or the start of exogenous feeding).

The changes in functional development and, consequently, in body form, which are especially dramatic during the few first days after hatching, lead to the formation of characteristic allometric growth patterns. The chronology of allometric changes is related to the chronology of important early life history events (Gisbert 1999). The HL growth of burbot larvae was positively allometric from hatching to day 20 (8.64 $\mathrm{mm}$ TL) and, during this time, structures and organs related to feeding and swimming developed sharply and prepared the fish for the pelagic stage. The early differentiation of the nervous (development of the midbrain and hindbrain), vision (positive allometric growth of the eyes) and feeding systems (positive allometric of the mouth) contribute to increasing the probability of zooplankton detection (Fuiman 1983; Koumoundouros et al. 1999). The development of 
gill arches and filaments would allow switching from temporary (cutaneous) to branchial respiration, resulting in a better oxygen supply and an increase in swimming activity (Gisbert et al. 2002). The swimming ability of burbot larvae to disperse actively in a water column to search for food, avoid potential predators and enhance their survival was progressively improved after swim bladder inflation. Swimming ability was concomitant with rapid development of the tail region (isometric growth of tail length and allometric growth in tail height), rapid development of the pectoral fins and differentiation of the primordial finfold into unpaired fins. The reported positive allometric growth of anterior and posterior parts of the body during the first stages of development in burbot larvae was not surprising, as it is common for many fish species to develop the anterior and posterior body regions prior to the abdominal part of body (Fuiman 1983; Osse et al. 1997; van Snik et al. 1997; Koumoundouros et al., 1999; Gisbert 1999; Gisbert et al. 2002). This growth pattern could also be interpreted as an adaptation to reduce and optimize the energy costs of larval transport (Osse and van den Boogaart 1995; 2004; van Snik et al. 1997)

The decrease in head height growth detected at $25.10 \mathrm{~mm}$ TL (44 DPH) and snout length at $27.85 \mathrm{~mm}$ TL (46 DPH) appears to be associated with the transition from a pelagic larva/juvenile into a benthic juvenile. This transition resulted in clear changes in proportions of the head, which became more elongated and flattened like in older stages. Other morphological changes related to the adaptation to a new (benthic) way of life are, for instance, fast growth of pelvic fins and an intensive increase in body pigmentation. Similar changes are characteristic for cod Gadus morhua L. and haddock Melanogrammus aeglefinus L. (Auditore et al. 1994). Another species which also shows transformation following the pelagic phase is the Californian halibut Paralichthys californicus, which undergoes progressive transition from a symmetrical (pelagic) larva into a bilaterally asymmetrical (benthic) juvenile. This transition results in profound changes in the organization of the splanchnocranium, especially the jaws and visceral arch skeleton (Gisbert et al. 2002).

In conclusion, organogenesis and differentiation in burbot larvae were more rapid and complex during the yolk sac and preflexion phase of development as larvae developed most of their sensorial, feeding, respiratory and swimming systems and, after notochord flexion, when most morphological changes were related to a progressive transformation from pelagic larva/juvenile to demersal larvae/juvenile. Besides these, all significant and rapid changes in body proportion concerned mainly the head region. Other body parts showed monophasic growth. The lack of inflexion points between $11.76 \mathrm{~mm}$ and $25.10 \mathrm{~mm}$ (24-44 DPH, flexion and most of the postflexion period) and the near-isometric growth of most body proportions during this period probably reflect long pelagic and prolonged transformation phases (between larval and juvenile stages) related to a gradual habitat shift from a pelagic to a demersal way of life. Such a growth timetable is in contrast with the general patterns in many teleost larvae, in which inflexion points occur within a more or less narrow TL interval. These occur most commonly during the flexion stage and are accompanied by the rapid development of fin rays, changes in body shape and a change in locomotive ability and feeding techniques (Kendall et al. 1984; van Snik et al. 1997; Gisbert 1999; Geerinckx et al. 2008; Peña and Dumas 2009).

The analysis of growth patterns in combination with observed changes in morphological development provides valuable information on the changes in functional demands throughout ontogeny. These models can be useful for both comparative studies of ontogeny in other species as well as for aquacultural applications by characterizing normal growth patterns. Moreover, the results presented in this study may be useful for aquaculturists 
since an understanding of developmental and growth patterns may lead to designing and providing more suitable rearing conditions for particular life stages.

Acknowledgments This study was cofinanced by the project "Innovations in finfish aquaculture with special reference to reproduction" (acronym: InnovaFish), Operational Programme "Sustainable Development of the Fisheries Sector and Coastal Fishing Areas 2007-2013" (OR14-61724-OR1400003/09/10/11).

Open Access This article is distributed under the terms of the Creative Commons Attribution License which permits any use, distribution, and reproduction in any medium, provided the original author(s) and the source are credited.

\section{References}

Auditore PJ, Lough RG, Broughton EA (1994) A review of the comparative development of Atlantic cod (Gadus morhua L.) and haddock (Melanogrammus aeglefinus L.) based on an illustrated series of larvae and juveniles from Georges Bank. NAFO science council studies, Northwest Atlantic Fisheries Organisation, pp 7-18

Donner MT, Eckmann R (2011) Diel vertical migration of larval and early-juvenile burbot optimises survival and growth in a deep, pre-alpine lake. Freshw Biol 56:916-925. doi:10.1111/j.1365-2427. 2010.02536.x

Dunn JR, Matarese AC (1984) Gadidae: development and relationships. In: Moser HG, Richards WJ, Cohen DM, Fahay MP, Kendall AW, Richardson WJ (eds) Ontogeny and systematics of fishes. Amer Soc Icht and Herp, Spec Pub, vol 1, pp 283-299

Fahay MP, Markle DF (1984) Gadiformes: Development and relationships. In: Moser HG, Richards WJ, Cohen DM, Fahay MP, Kendall AW, Richardson WJ (eds) Ontogeny and systematics of fishes. Amer Soc Icht and Herp, Spec Pub, vol 1, pp 265-283

Fischer P (1999) Otolith microstructure during the pelagic, settlement and benthic phases in burbot. J Fish Biol 54:1231-1243

Fuiman LA (1983) Growth gradients in fish larvae. J Fish Biol 23:117-123

Geerinckx T, Verhaegen Y, Adriaens D (2008) Ontogenetic allometries and shape changes in the suckermouth armoured catfish Ancistrus cf. triradiatus Eigenmann (Loricariidae, Siluriformes), related to suckermouth attachment and yolk-sac size. J Fish Biol 72:803-814

Ghan D, Sprules WG (1993) Diet, prey selection, and growth of larval and juvenile burbot Lota lota (L.). J Fish Biol 42:47-64

Gisbert E (1999) Early development and allometric growth patterns in Siberian sturgeon and their ecological significance. J Fish Biol 54:852-862

Gisbert E, Merino G, Muguet JB, Bush D, Piedrahita RH, Conklin DE (2002) Morphological development and allometric growth patterns in hatchery-reared California halibut larvae. J Fish Biol 61:1217-1229

Hardy R, Paragamian VL, Neufeld MD (2008) Zooplankton communities and burbot relative abundance of some oligotrophic Lakes of Idaho, USA and British Columbia, Canada. Am Fish Soc Symp 59:79-89

Harzevili AS, De Chareloy D, Auwerx A, Vught I, Van Slycken J, Dhert P, Sorgeloos P (2003) Larval rearing of burbot (Lota lota L.) using Brachionus calyciflorus rotifer as started food. J Appl Ichthyol 19:84-87

Harzevili AS, Dooremont I, Vught I, Auwerx J, Quataert P, De Charleroy D (2004) First feeding of burbot, Lota lota (Gadidae, Teleostei) larvae under different temperature and light conditions. Aquac Res 35:49-55

Heming TA, Buddington RK (1988) Yolk sac absorption in embryonic and larval fishes. In: Hoar WS, Randall DJ (eds) Fish physiology, vol 11. Academic Press, New York, pp 407-446

Hofmann N, Fischer P (2001) Seasonal changes in abundance and age structure of burbot Lota lota (L.) and stone loach Barbatula barbatula (L.) in the littoral zone of a large pre-alpine lake. Ecol Freshw Fish 10:21-25

Kendall AW, Ahlstrom EH, Moser HG (1984) Early life history stages of fishes and their characters. In: Moser HG, Richards WJ, Cohen DM, Fahay MP, Kendall AW, Richardson SL (eds) Ontogeny and systematics of fishes: American Society of Ichthyologists and Herpetologists, Special Publication No. 1. Allen Press Inc, Lawrence, KS, pp 11-22

Koumoundouros G, Divanach P, Kentouri M (1999) Ontogeny and allometric plasticity of Dentex dentex (Osteichthyes: Sparidae) in rearing conditions. Mar Biol 135:561-572 
Lahnsteiner F, Kletzl M, Weismann T (2012) The effect of temperature on embryonic and yolk-sac larval development in the burbot Lota lota. J Fish Biol 81:977-986. doi:10.1111/j.1095-8649.2012.03344.x

McPhail JD, Paragamian VL (2000) Burbot biology and life history. In: Paragamian VL, Willis DH (eds) Burbot biology, ecology, and management. American Fisheries Society, Fisheries Management Section Publication Number 1, Bethesda, Maryland, pp 11-23

Osse JW, van den Boogaart JGM (1995) Fish larvae, development, allometric growth, and the aquatic environment. Int Council Exp Sea Mar Sci Symp 201:21-34

Osse JW, van den Boogaart JGM (2004) Allometric growth in fish larvae: timing and function. In: Govoni JJ (ed) The development of form and function in fishes and the question of larval adaptation. American Fisheries Society, symposium 40, Bethesda, MD, pp 167-194

Osse JWM, van den Boogaart JGM, van Snik GMJ, van der Sluys L (1997) Priorities during early growth of fish larvae. Aquaculture 155:249-258

Paragamian VL, Pyper BJ, Daigneault MJ, Beamesderfer RCP, Ireland SC (2008) Population dynamics and extinction risk of burbot in the Kootenai River, Idaho, USA and British Columbia, Canada. Am Fish Soc Symp 59:213-234

Peña R, Dumas S (2009) Development and allometric growth patterns during early larval stages of the spotted sand bass Paralabrax maculatofasciatus (Percoidei: Serranidae). Sci Mar 73S1:183-189

Ryder RA, Pesendorfer J (1992) Food, growth, habitat, and community interactions of young-of-the-year burbot, Lota lota L., in a Precambrian shield lake. Hydrobiologia 243/244:211-227

van Houdt JK, Hellemans B, Volckaert FA (2003) Phylogenetic relationships among Palearctic and Nearctic burbot (Lota lota): Pleistocene extinctions and recolonisation. Mol Phylogenet Evol 29:599-612. doi:10.1016/S1055-7903(03)00133-7

van Houdt JK, de Cleyn L, Perretti A, Volckaert FAM (2005) A mitogenic view on the evolutionary history of the Holarctic freshwater gadoid, burbot (Lota lota). Mol Ecol 14:2445-2457. doi:10.1111/j.1365294X.2005.02590.x

van Snik GMJ, van den Boogaart JGM, Osse WM (1997) Larval growth patterns in Cyprinus carpio and Clarias gariepinus with attention to the finfold. J Fish Biol 50:1339-1352

Wang N, Appenzeller A (1998) Abundance, depth distribution, diet composition and growth of perch (Perca fluviatilis) and burbot (Lota lota) larvae and juveniles in the pelagic zone of Lake Constance. Ecol Freshw Fish 7:176-183

Wocher H, Harsányi A, Schwarz JF (2013) Larviculture of burbot (Lota lota L.): larval rearing using Artemia and weaning onto dry feed. Aquac Res 44:106-113. doi:10.1111/j.1365-2109.2011.03015.x

Wolnicki J, Kamiński R, Myszkowski L (2002) Temperature-influenced growth and survival of burbot Lota lota (L.) larvae fed live food under controlled conditions. Arch Pol Fish 10:109-113

Żarski D, Sasinowski W, Kucharczyk D, Kwiatkowski M, Krejszeff S, Targońska K (2009) Mass initial rearing of burbot Lota lota (L.) larvae under controlled conditions. Pol J Nat Sci 24:76-84 